\title{
Caracterização Gravimétrica dos Resíduos Sólidos de um Aterro Sanitário Municipal no Interior do Estado de São Paulo
}

Gravimetric Characterization of Solid Waste at a Municipal Landfill in São Paulo State

Caracterización Gravimétrica de los Residuos Sólidos de un Vertedero Municipal en el Estado de São Paulo

Evandro Roberto Tagliaferro

Professor Doutor, Universidade Brasil, Brasil evandro.tagliaferro@universidadebrasil.edu.br

David Valpassos Viana

Universidade de São Paulo, Brasil. davidviana@gmai.com 


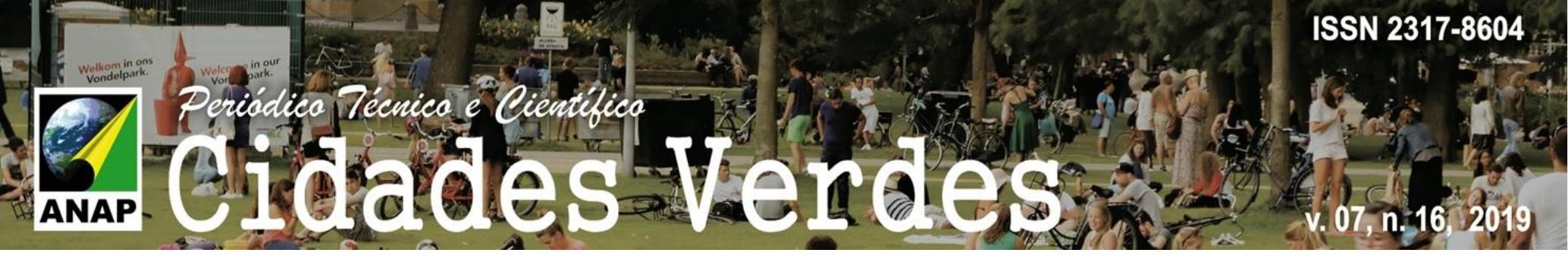

RESUMO

O trabalho objetivou caracterizar os resíduos sólidos urbanos de um aterro municipal no interior do Estado de São Paulo, obtendo parâmetros para análise da eficiência do sistema de triagem e segregação de resíduos encaminhados para a reciclagem. A metodologia de quarteamento foi adotada em conjunto com adaptações de diversos autores e recomendações de manuais técnicos. Realizado em conformidade com normas específicas, em especial a NBR 10.007/04, os dados constataram que o município desenvolve ações junto à geração de resíduos que devem ser aprimoradas. A caracterização identificou aumento na quantidade de plástico e diminuição de vidro, metal, papel e papelão. As variações decorrem de ações individualizadas de agentes como: catadores, empresas de sucatas e cooperativa.

PALAVRAS-CHAVE: Quarteamento. Caracterização. Resíduos, Eficiência, Reciclagem.

\begin{abstract}
The goal of this paper was to characterize the urban solid waste found at a municipal landfill in the state of São Paulo, in order to obtain parameters for analyzing the efficiency of the sorting and segregation systems of the waste sent to recycling. The quartering method was adopted together with adaptations of various authors and recommendations found in technical manuals. The findings of the study, which was performed in compliance with specific norms, particularly NBR 10.007/04, verified that the city in question develops actions concerning waste generation that should be improved. The characterization identified an increase in the amount of plastic materials and a reduction in the amount of glass, metal, paper, and cardboard. These fluctuations are a result of individualized actions of agents such as cardboard collectors, scrap metal companies, and cooperatives.
\end{abstract}

KEYWORDS: Quartering. Characterization. Refuse, Efficiency, Recycling.

\title{
RESUMEN
}

El objetivo del trabajo fue caracterizar los residuos sólidos urbanos de un vertedero municipal en el Estado de São Paulo, obteniendo parámetros para analizar la eficiencia del sistema de clasificación y de segregación de los residuos enviados al reciclaje. Se ha adoptado el método de cuarteamiento juntamente con adaptaciones de diversos autores y recomendaciones de manuales técnicos. Los datos del estudio, obtenidos de conformidad con normas específicas, en especial con la NBR 10.007/04, han constatado que el municipio en cuestión desarrolla acciones relativas a la generación de residuos que deben ser mejoradas. La caracterización ha identificado un aumento en la cantidad de plástico y una reducción en la cantidad de vidrio, metal, papel y cartón. Estas variaciones son el resultado de acciones individualizadas de agentes tales como: cartoneros, empresas de chatarra y cooperativas.

PALABRAS CLAVE: Cuarteamiento. Caracterización. Residuos, Eficiencia, Reciclaje. 


\section{INTRODUÇÃO}

A busca por informações essenciais para a avaliação dos sistemas de gerenciamento de resíduos e a possibilidade de identificação de parâmetros que permitam seu aprimoramento mostra-se de extrema necessidade diante da realidade atual que vivemos.

O constante crescimento da população, a consequente geração de resíduos e as dificuldades na efetivação de soluções plausíveis a curto prazo evidenciam o problema e ratificam a necessidade de conhecermos mais precisamente os materiais presentes nos resíduos, possibilitando uma maior compreensão da dinâmica que envolve sua geração, descarte e alternativas de tratamento.

Essa compreensão mais ampla possibilita o desenvolvimento e a busca de soluções mais adequadas, bem como a avaliação dos sistemas atualmente implantados de gerenciamento.

Analisar a composição da massa de resíduos, identificando a quantidade dos materiais que a compõem, por meio da determinação de sua composição gravimétrica, permite inferir diferenças de resultado do sistema em função de variáveis econômicas, políticas, sazonais e climáticas, bem como questões de natureza cultural. E serve ainda como ferramenta para analisar a eficiência ou não dos sistemas, permitindo parâmetros para analisar o sistema de gerenciamento e subsidiar a formação de políticas mais efetivas de intervenção, educação e gestão (SCHENEIDER et al, 2003).

Assim, o estudo gravimétrico, apesar de uma ferramenta simples, é de extrema importância para a definição de estratégias locais e regionais que atendam à hierarquização das ações com os resíduos, tal como determinado pela Política Nacional dos Resíduos Sólidos (PNRS), entre outras várias questões correlatas.

Segundo Monteiro et al (2002), os exemplos básicos de cada categoria de resíduos sólidos urbanos são: matéria orgânica putrescível, plástico, papel e papelão, vidro, metal ferroso, metal não-ferroso, madeira, têxtil, contaminantes químicos, contaminantes biológicos, inertes, diversos e outros materiais de difícil identificação.

Neste contexto, o presente trabalho objetivou caracterizar os resíduos sólidos urbanos de um aterro municipal no interior do Estado de São Paulo, obtendo parâmetros para análise da eficiência do sistema de triagem e segregação de resíduos encaminhados para a reciclagem.

A metodologia de quarteamento foi adotada em conjunto com adaptações de diversos autores e recomendações de manuais técnicos. E realizada em conformidade com normas específicas, em especial as NBR 10.004/04 e NBR 10.007/04.

Os dados constataram que o município desenvolve ações junto à geração de resíduos que devem ser aprimoradas (incentivo a não geração e fomento de iniciativas de segregação e reciclagem). A caracterização identificou ainda um aumento na quantidade de plástico e diminuição de vidro, metal, papel e papelão. As variações decorrem de ações individualizadas de agentes como: catadores, empresas de sucatas e cooperativa. 


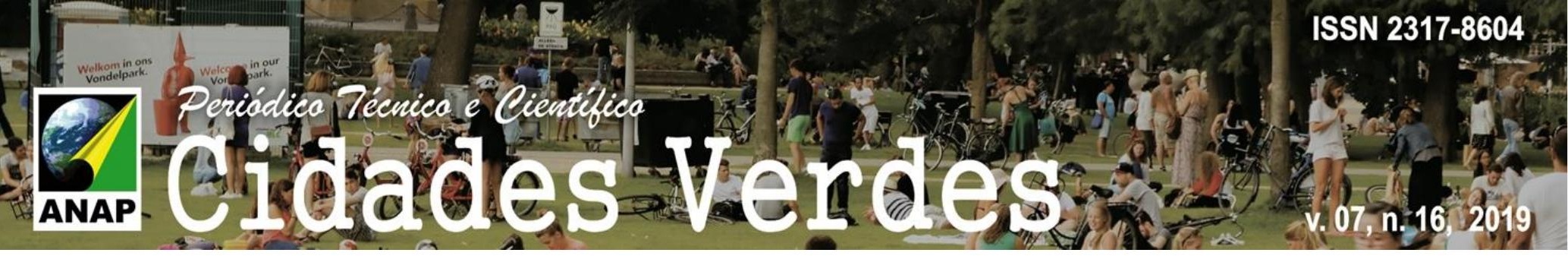

\section{OBJETIVOS}

\subsection{OBJETIVO GERAL}

Caracterizar os resíduos sólidos urbanos de um aterro municipal no interior do Estado de São Paulo, obtendo parâmetros para análise da eficiência do sistema de triagem e segregação de resíduos encaminhados para a reciclagem.

\subsection{OBJETIVOS ESPECÍFICOS}

- Caracterizar os resíduos dispostos no aterro sanitário municipal por meio de estudo gravimétrico;

- Identificar e analisar os resultados quantitativos e percentuais de participação de cada resíduos decorrentes da caracterização;

- Colaborar para o entendimento quanto aos resultados obtidos e os atores envolvidos na triagem e segregação dos resíduos objetivando a reciclagem.

\section{METODOLOGIA / MÉTODO DE ANÁLISE}

\subsection{Breve Caracterização do Município}

O município objeto de estudo localiza-se na região de Campinas, no centro-leste paulista, onde ocupa uma área de $270,90 \mathrm{~km}^{2}$, com uma população total estimada de 183.720 habitantes (SEADE, 2014), sendo que $99,22 \%$ vivem na área urbana.

A coleta de resíduos é efetuada em $100 \%$ dos domicílios da área urbana. Possui aterro sanitário municipal que recebe em média 115,6 toneladas por dia de resíduos, totalizando uma média mensal de 3.468 toneladas, com uma média de geração per capta de 0,642 $\mathrm{Kg} / \mathrm{habitante}$ dia.

O clima na região é classificado como mesotérmico do tipo temperado das latitudes médias (NIMER, 1979), mais especificamente tropical de altitude. De acordo com a classificação de Köppen se enquadra na categoria $\mathrm{Cw}$ que corresponde a clima úmido com invernos amenos e secos. Assim, a região recebe entre 1200 e 1500 milímetros de chuva anualmente, que corresponde a uma região com regime de precipitação moderada.

O balanço hídrico indica excedente de dezembro a março, sendo que na maior parte dos meses há déficit hídrico, o que é fator importante, pois é redutor de geração de líquidos percolados no Aterro Sanitário, além de viabilizar futuros programas de reciclagem e compostagem que possam ser desenvolvidos.

Em relação a geologia e relevo, a área está na chamada Depressão Periférica Paulista (ALMEIDA, 1964) a qual consiste em um corredor de topografia colinosa de, aproximadamente 50 a $120 \mathrm{~km}$ de largura. E no caso, em faixa de ocorrência das sequências sedimentares infrabasálticas paleozóicas e mesozóicas do Estado de São Paulo, como se observa em vários pontos ao longo da cidade com afloramentos rochosos com diques e sills de diabásio. 


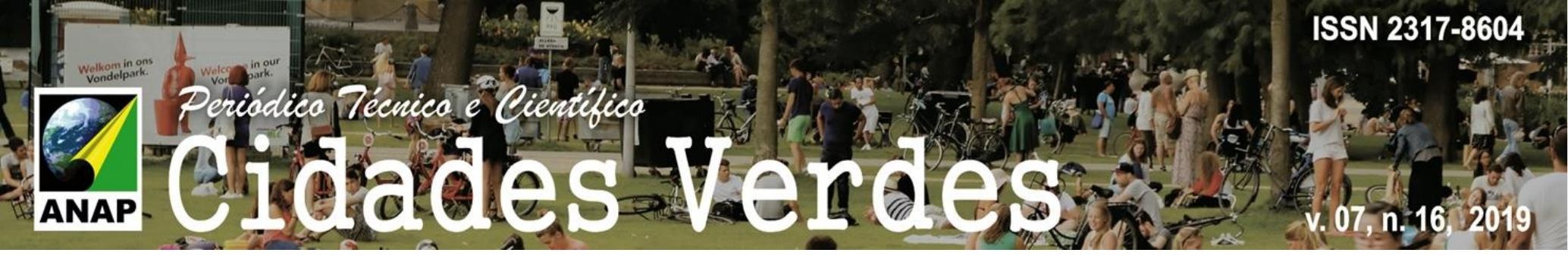

\subsection{Caracterização dos Resíduos}

O aterro sanitário foi construído a 3.800 metros do núcleo urbano principal, perto da grande massa geradora de resíduos. E recebe os seguintes resíduos:

- Resíduos Domiciliares: coletados por caminhões particulares e equipamentos da própria Prefeitura Municipal.

- Resíduos Comerciais: gerados em estabelecimentos comerciais, cujas características dependem da atividade desenvolvida.

- Resíduos Inertes: móveis velhos, resíduos recicláveis ou dispostos para reciclagem.

- Resíduos orgânicos: Varrição, Poda de Árvores, Coleta de Feiras.

- Materiais Recicláveis: rejeitos de processos de reciclagem que eventualmente ficaram sem mercado.

A caracterização concentrou-se na quantidade dos resíduos separados e suas respectivas porcentagens sobre o peso da amostra que foi coletada após os procedimentos do quarteamento.

Para que não houvesse distorções (nas amostras e nos resultados) as amostragens foram realizadas em dias da semana representativos, de áreas de coleta com diferentes perfis, distantes de feriados ou eventos intercorrentes.

Os setores escolhidos para amostragem foram selecionados de acordo com o nível socioeconômico. O objetivo foi obter no quarteamento e amostragem dados médios representativos de toda a cidade, considerando ainda uma heterogeneidade proporcional, ou seja, as amostras corresponderem proporcionalmente os tipos de bairros da cidade.

Foram coletadas amostras nos seguintes setores (Quadro 1): 


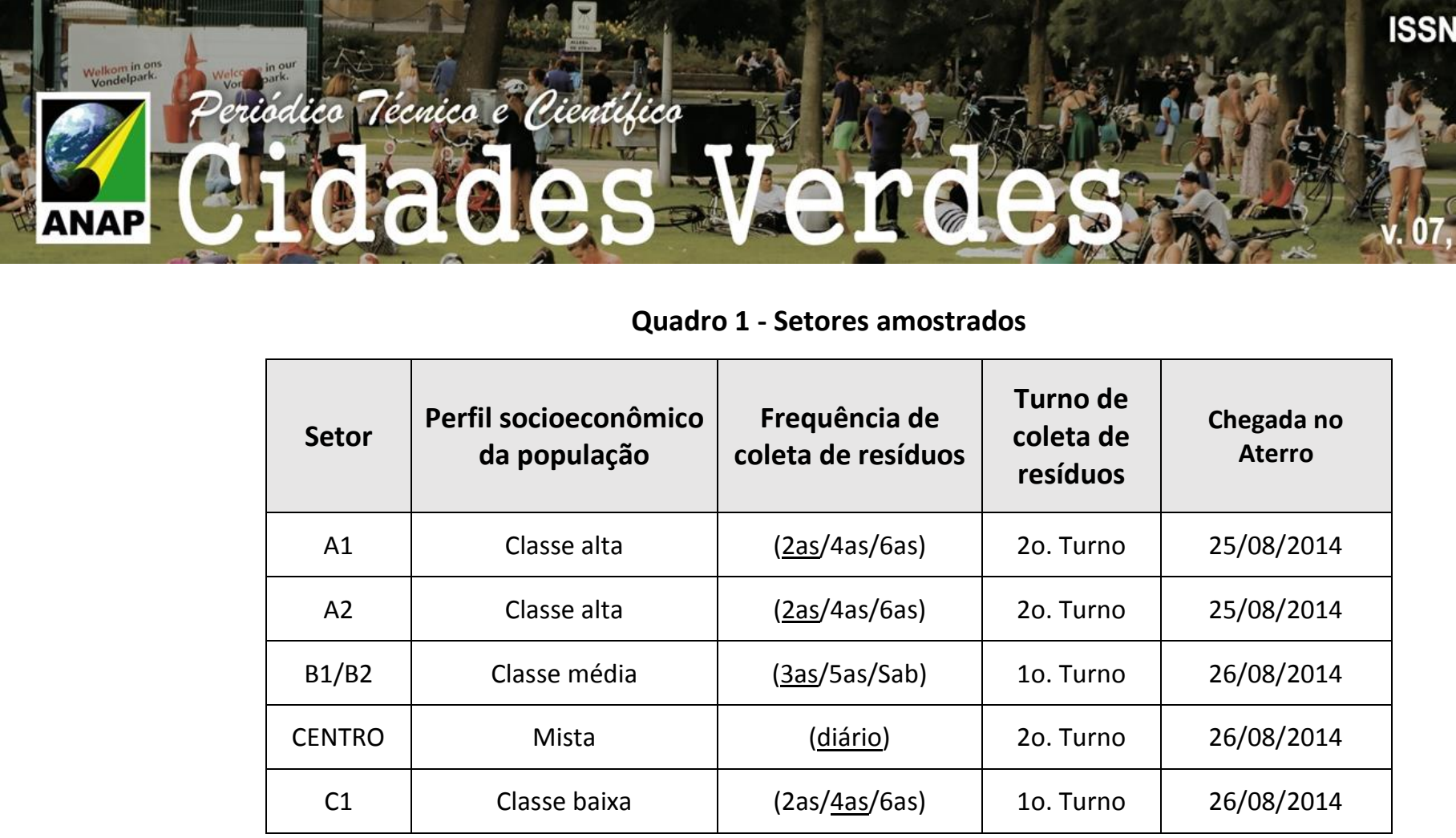

Fonte: Próprio autor

O quarteamento e as amostragens foram obtidas em uma área plana, específica, no aterro sanitário, em local próximo a descarga dos caminhões coletores de resíduos. Área com espaço para o trator realizar os procedimentos, facilitando assim o manejo, tanto para as amostragens quanto para o descarte dos materiais.

Os tambores recolhidos com o método do quarteamento foram transportados até outra área, coberta, perto da entrada do aterro, onde foram analisados os resíduos. Os Materiais utilizados no processo foram EPI's (luvas, botas), ferramentas (pás, enxadas e facas), instrumentos de mensuração, recipientes de coleta e armazenamento (tambores de $120 \mathrm{~L}$ ).

As amostragens foram retiradas a partir dos caminhões coletores provenientes dos setores relacionados anteriormente, totalizando oito caminhões.

Para a determinação da composição gravimétrica foi utilizada a técnica de quarteamento proposta por Pessin et al (2006), adaptada, sempre em conformidade com as normas técnicas (NBR 10004/2004 e NBR 10007/2004), seguindo as seguintes etapas (Figuras 1, 2 e 3):

1) Descarga dos resíduos de um caminhão e rompimento dos sacos para homogeneização da amostra universal;

2) Anotação do peso do caminhão para identificação do tamanho da amostra;

3) Preenchimento de 10 bombonas de 120 litros com a retirada de amostras de 05 pontos (01 no centro e 04 nos quadrantes);

4) O conteúdo então foi despejado sobre a lona plástica e iniciado o processo de homogeneização da amostra;

5) Dos 1.200 litros foram efetuados dois quarteamentos (com descarte vis-à-vis) até a obtenção de uma amostra de 240 litros; 


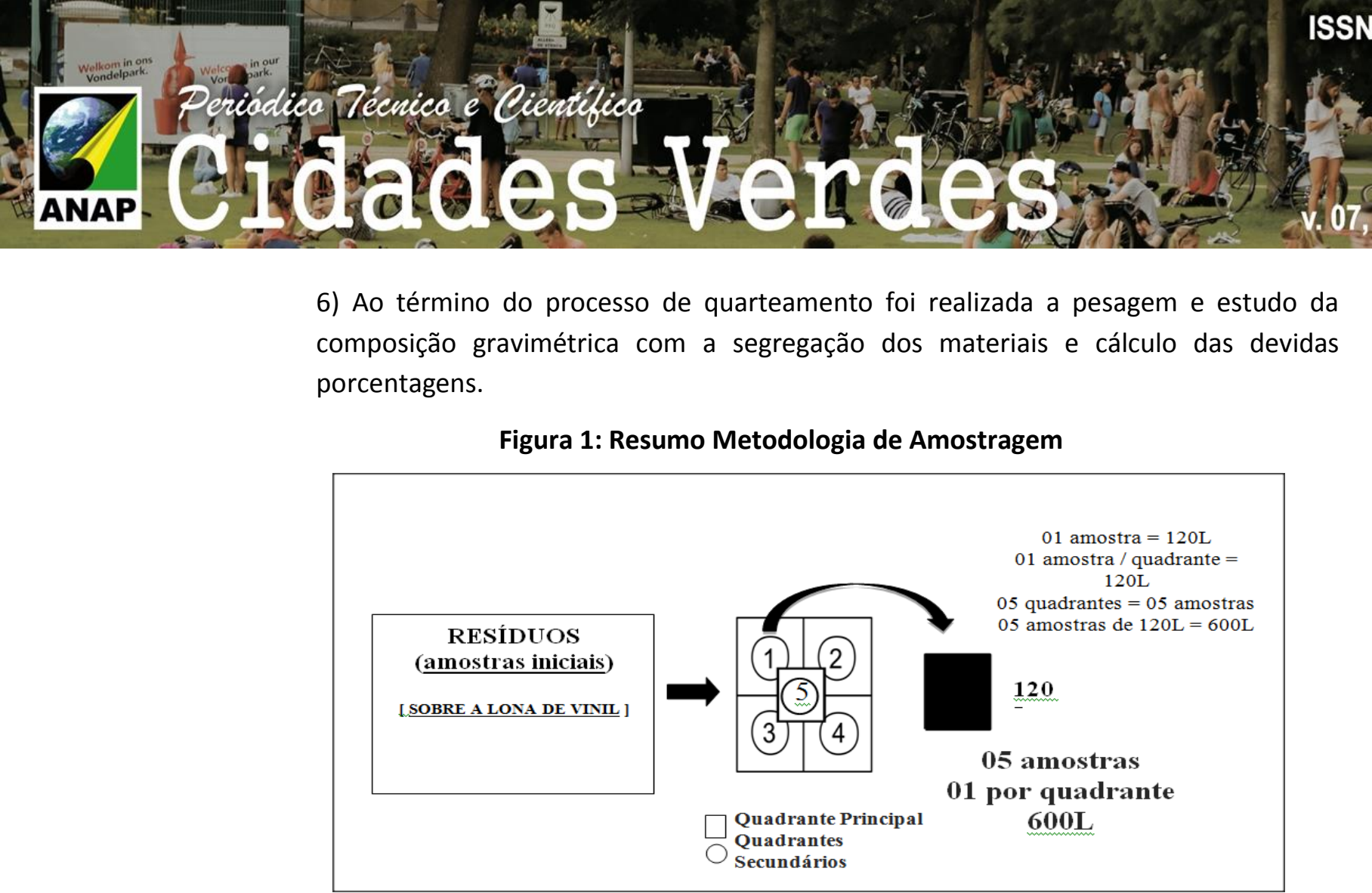

6) Ao término do processo de quarteamento foi realizada a pesagem e estudo da composição gravimétrica com a segregação dos materiais e cálculo das devidas porcentagens.

Figura 1: Resumo Metodologia de Amostragem

Fonte: Próprio autor

Figura 2 - Inserção dos resíduos pré-amostrados para quarteamento.

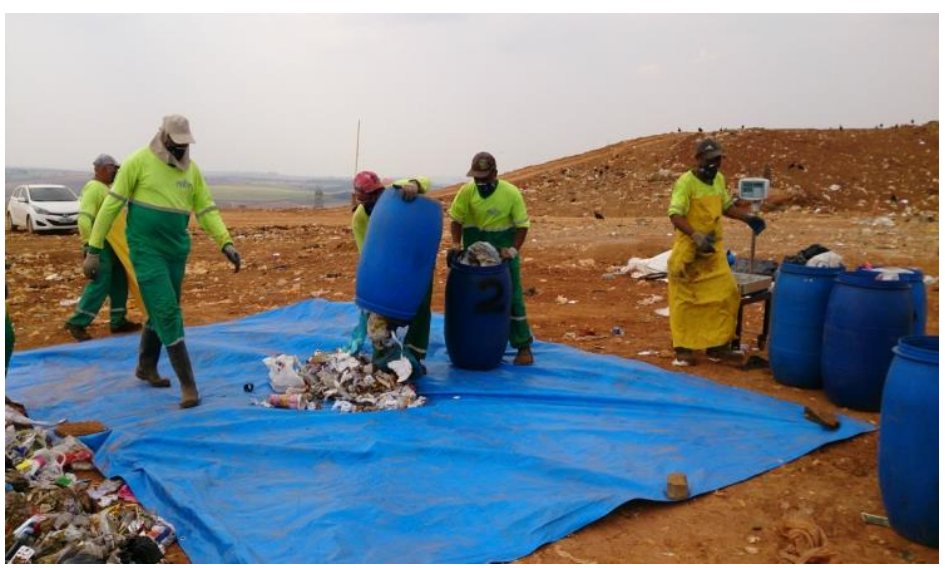

Fonte: Próprio autor 


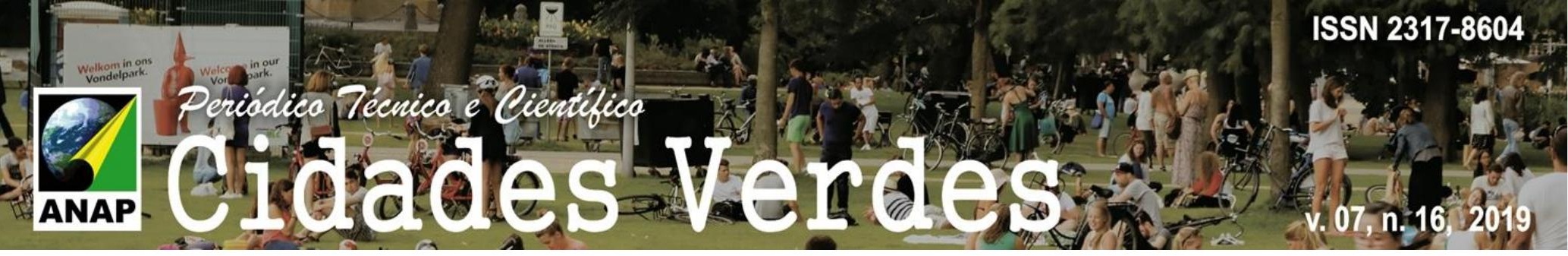

Figura 3 - Pesagem e Tara da pré-amostra para a seleção de amostra final em quarteamento

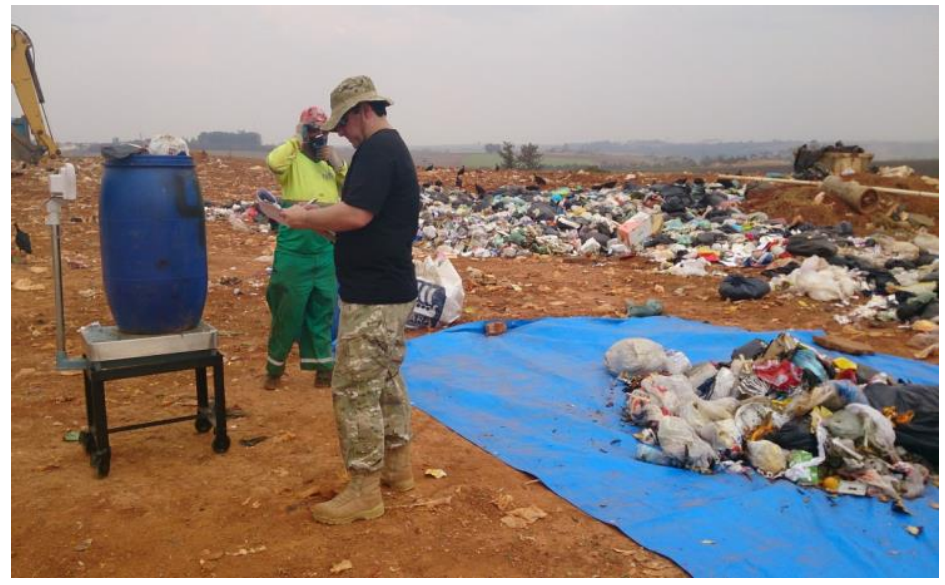

Fonte: Próprio autor

A separação dos materiais resultou do seguinte procedimento (Figuras 4):

a) O Big Bag contendo a amostra final daquele setor escolhido foi descarregado cuidadosamente em uma mesa de separação instalada no barracão (área coberta);

b) Os tambores, anteriormente utilizados para extração de amostras, receberam outras marcações, indicando quais materiais seriam neles dispostos durante o processo de separação (triagem) da Amostra Final (por setor);

c) A amostra final (por setor) foi separada em: Papel e Papelão, Metal, Vidros, Plástico PET, Plástico Duro, Plástico Mole, Indiferenciados, Orgânicos;

d) Cada tambor contendo o respectivo material foi pesado e planilhado;

e) A planilha de cada setor analisado indica os dados encontrados para cada um dos materiais acima listados indicando: Peso bruto, Tara do Tambor/Bombona/Bomba Plástica ou Saco Plástico, Peso líquido (Peso bruto extraído a Tara).

Foram utilizadas 02 balanças digitais de precisão, uma de piso, com divisão de 05 gramas, carga mínima de 100 gramas e carga máxima de $130 \mathrm{~kg}$. e outra de mesa, com divisão de 0,5 grama, carga mínima de 20 gramas e carga máxima de $30 \mathrm{~kg}$.

Os materiais, após a separação e pesagem individual, foram reacondicionados nos Big Bag's e descartados no aterro. 


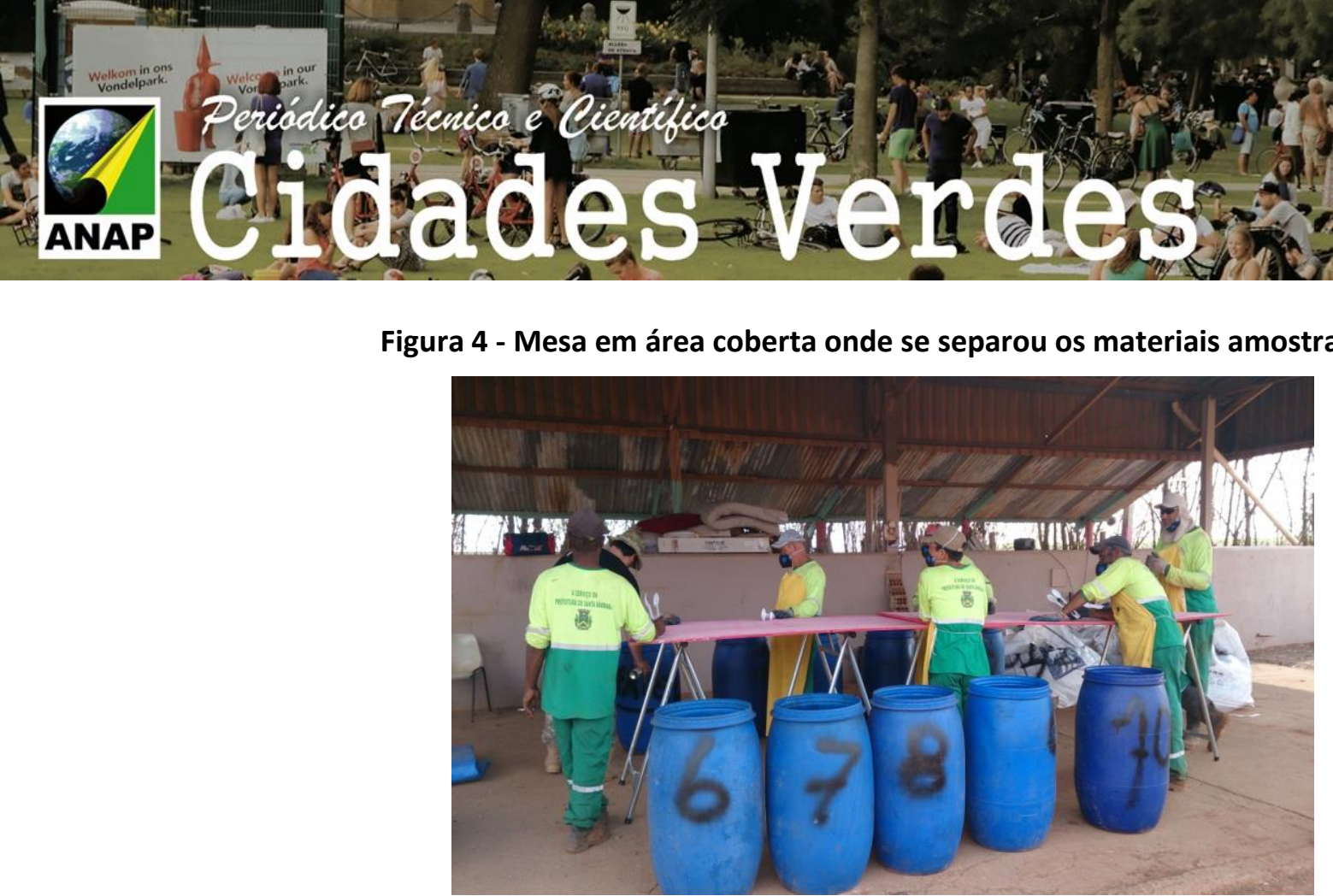

Fonte: Próprio autor

A partir das amostras realizou-se o processo de caracterização, pesando-se os constituintes separados, sempre descontando o peso dos tambores (tara), previamente pesados (Figura 5).

Figura 5 - Separação dos resíduos de cada amostra para pesagem

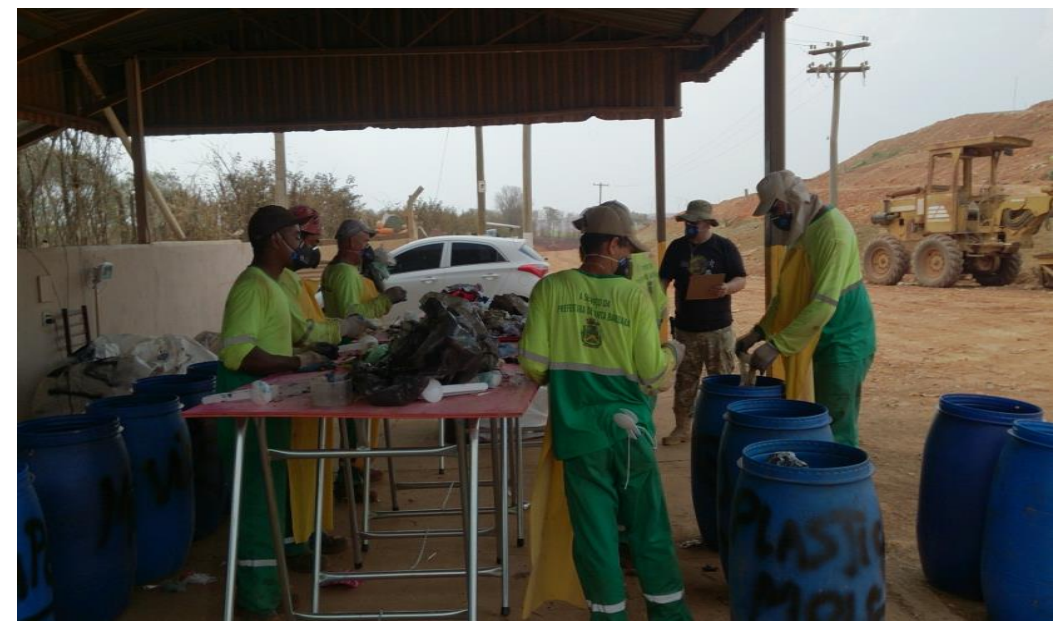

Fonte: Próprio autor

Os resíduos foram separados em Papel e Papelão, Metal, Vidros, Plástico PET, Plástico Rígido, Plástico Mole, Indiferenciados e Orgânicos. Foram classificados como "indiferenciados" todos os materiais que não se enquadraram na lista dos componentes, por possuírem características diferenciadas ou por não ser possível a identificação.

Após a separação e pesagem foram calculadas as porcentagens de cada classe separadamente, conforme o seguinte cálculo: Material $(\%)=$ Peso do Material $(\mathrm{Kg})$ x $100 \div$ Peso Total da Amostra Final (kg). (Figuras 6a e 6b) 


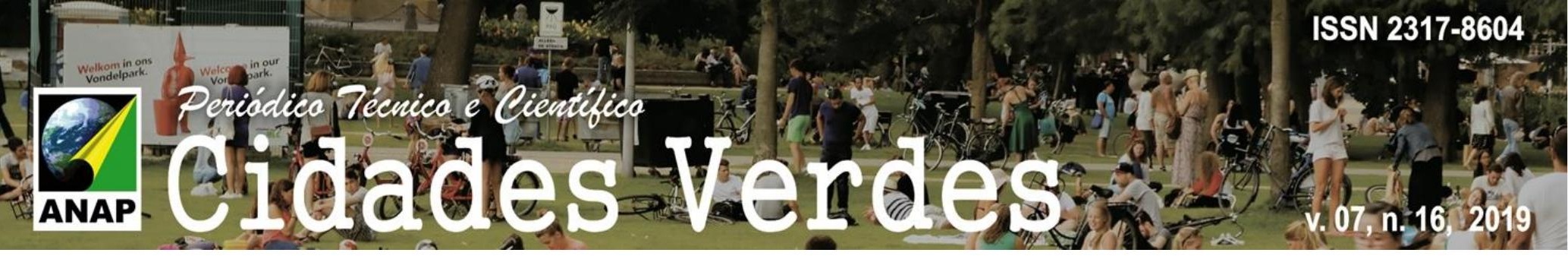

\section{CONCLUSÃO}

Pode-se constatar que o município desenvolve ações eficazes em relação à geração de resíduos, caracterizada pela diminuição na quantidade de alguns materiais recicláveis encaminhados ao aterro, como: vidro, papel e metal. Tais atividades são desenvolvidas pela chamada "reciclagem privada", uma vez que identificados diversos sucateiros e ferros velhos na cidade, além da cooperativa de catadores de materiais recicláveis. Quatro Ecopontos recebem resíduos da construção civil (RCC) e resíduos recicláveis, os quais também são encaminhados para a cooperativa.

Especificamente no segundo semestre de 2014, alguns plásticos, em especial plástico mole, não encontrou saída para comercialização (viabilidade técnica e econômica para reinserção junto ao mercado), além de ser cada vez maior o uso de embalagens plásticas. Estes fatores por si podem explicar o percentual de plásticos acima do esperado.

As disparidades nos resultados encontrados podem ser mais bem equalizadas com ajustes no mercado de reciclagem e a implantação de programas específicos para reaproveitamento, reutilização e reciclagem do plástico, além de exigir regulamentação da legislação para fabricantes de embalagens sustentáveis, o que basicamente são políticas estaduais e federais.

\section{REFERÊNCIAS BIBLIOGRÁFICAS}

ALMEIDA, F. F. M. de. Fundamentos geológicos do relevo paulista. Boletim do Instituto de Geografia e Geologia, São Paulo, n. 41, 1964

ASSOCIAÇÃO BRASILEIRA DE NORMAS TÉCNICAS - ABNT. (NBR 10.004). Resíduos sólidos - Classificação. 2004.

ASSOCIAÇÃO BRASILEIRA DE NORMAS TÉCNICAS - ABNT. (NBR 10.007). Amostragem de resíduos sólidos. 2004.

BRASIL. MINISTÉRIO DO MEIO AMBIENTE. Plano Nacional de Resíduos Sólidos. Versão pós Audiências e Consulta Pública para Conselhos Nacionais. Brasília: MMA/SRHU. 2012. 104 p.

CHERNICHARO, C. A. L; COSTA, B. M. P; LIBÂNIO, P. A. C; CINTRA, I. S. Avaliação de metodologia de amostragem para caracterização física de resíduos sólidos urbanos. 22을 Congresso Brasileiro de Engenharia Sanitária e Ambiental. Joinville - Santa Catarina - SC, 2003.

MONTEIRO, José H. P. Manual Integrado de Gerenciamento de resíduos sólidos, Rio de Janeiro: IBAM - SEDU/PR, 2002.

NIMER, E. Clima da Região Sudeste. In: Geografia do Brasil. Rio de Janeiro/IBGE, 1971 Climatologia do Brasil. IBGE Rio de Janeiro: 1979.

PELLEGRINO, S. A. C. Gestão de Resíduos Sólidos Urbanos em município de pequeno porte: sistematização de diretrizes e procedimentos. São Carlos - SP, 2003.

PEREIRA NETO, J. T.; Gerenciamento do lixo urbano: aspectos técnicos e operacionais. Viçosa: UFV, 2007

PESSIN, N. et al. Métodos de Transformação e Aproveitamento da Fração Orgânica: Minimização da Quantidade de Resíduos Dispostos em Aterro. In: CASTILHOS JUNIOR, A.B. (Org.) Gerenciamento de Resíduos Sólidos Urbanos com Ênfase na Proteção de Corpos D'água: Prevenção, Geração e Tratamento de Lixiviados de Aterros Sanitários. Rio de Janeiro: ABES, 2006. P. 17-63.

PRANDINI, L. F; JARDIM, N. S; D'ALMEIDA, M. L. O. Lixo Municipal: Manual de gerenciamento integrado. São Paulo: 1995. 
